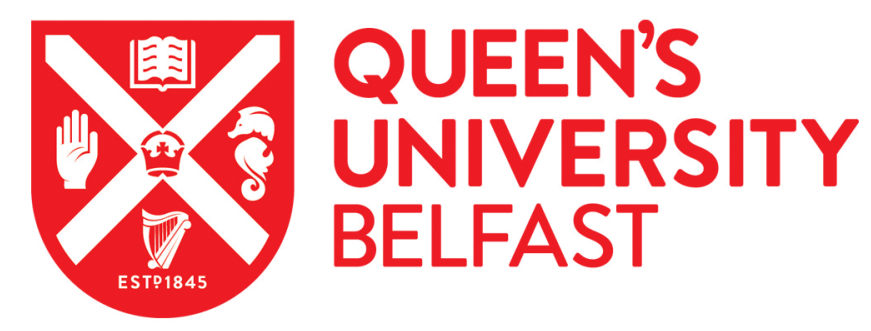

\title{
Identification of tone duration, line length and letter position: An experimental approach to timing and working memory deficits in schizophrenia.
}

Elvevag, B., Brown, G. D. A., McCormack, T., Vousden, J. I., \& Goldberg, T. E. (2004). Identification of tone duration, line length and letter position: An experimental approach to timing and working memory deficits in schizophrenia. Journal of Abnormal Psychology, 113(4)(4), 509-521. https://doi.org/10.1037/0021843X.113.4.509

\section{Published in:}

Journal of Abnormal Psychology

\section{Document Version:}

Publisher's PDF, also known as Version of record

Queen's University Belfast - Research Portal:

Link to publication record in Queen's University Belfast Research Portal

\section{General rights}

Copyright for the publications made accessible via the Queen's University Belfast Research Portal is retained by the author(s) and / or other copyright owners and it is a condition of accessing these publications that users recognise and abide by the legal requirements associated with these rights.

Take down policy

The Research Portal is Queen's institutional repository that provides access to Queen's research output. Every effort has been made to ensure that content in the Research Portal does not infringe any person's rights, or applicable UK laws. If you discover content in the

Research Portal that you believe breaches copyright or violates any law, please contact openaccess@qub.ac.uk. 


\title{
Identification of Tone Duration, Line Length, and Letter Position: An Experimental Approach to Timing and Working Memory Deficits in Schizophrenia
}

\author{
Brita Elvevåg \\ National Institute of Mental Health \\ Teresa McCormack \\ Queen's University
}

\author{
Gordon D. A. Brown \\ Warwick University \\ Janet I. Vousden \\ Warwick University
}

\author{
Terry E. Goldberg \\ National Institute of Mental Health
}

\begin{abstract}
Patients with schizophrenia display numerous cognitive deficits, including problems in working memory, time estimation, and absolute identification of stimuli. Research in these fields has traditionally been conducted independently. We examined these cognitive processes using tasks that are structurally similar and that yield rich error data. Relative to healthy control participants $(n=20)$, patients with schizophrenia $(n=20)$ were impaired on a duration identification task and a probed-recall memory task but not on a line-length identification task. These findings do not support the notion of a global impairment in absolute identification in schizophrenia. However, the authors suggest that some aspect of temporal information processing is indeed disturbed in schizophrenia.
\end{abstract}

Patients with schizophrenia present with a wide range of cognitive deficits. We take as our starting premise the idea that these cognitive deficits may be at the core of the illness (for a review, see Elvevåg \& Goldberg, 2000). Therefore, understanding the exact nature of the deficits promises to provide useful clues as to the cognitive architecture of dysfunction. In this article, we present an attempt to synthesize certain deficits in schizophrenia that have traditionally been examined within separate frameworks. More specifically, we argue that patients with schizophrenia do not show

Brita Elvevåg and Terry E. Goldberg, Clinical Brain Disorders Branch, National Institute of Mental Health/National Institutes of Health (NIMH/ NIH); Gordon D. A. Brown and Janet I. Vousden, Department of Psychology, Warwick University, Coventry, United Kingdom; Teresa McCormack, Department of Psychology, Queen's University, Belfast, United Kingdom.

This research was supported by a cooperative group award (Grant G9805928) from the Medical Research Council, United Kingdom; Grant R000239002 (to Teresa McCormack and Gordon D. A. Brown) and Grant R000239351 (to Gordon D. A. Brown, Nick Chater, Koen Lamberts, and Neil Stewart) from the Economic and Social Research Council, United Kingdom; and Grant 88/S15050 (to Gordon D. A. Brown and Teresa McCormack) from the Biotechnology and Biological Sciences Research Council, United Kingdom. We are grateful to Abigail L. Gilbert and K. Megan Kerbs for assistance with data collection and Danny Weinberger for useful suggestions.

Correspondence concerning this article should be addressed to Brita Elvevåg, Clinical Brain Disorders Branch, NIMH/NIH, Building 10, Rm. 4S235, Building 10, MSC 1379, Bethesda, MD 20892. E-mail: elvevaab@intra.nimh.nih.gov a general deficit in the identification of stimuli on the basis of their magnitudes but are instead selectively impaired in identifying temporal durations and temporal order information when comparable tasks are used.

The first line of research concerns findings that patients with schizophrenia display deficits on a variety of tasks that require short-term or working-memory abilities. For example, memory ability can be evaluated in a probed-recall task in which a series of letters (e.g., $A B C D E F$ ) is presented and participants are subsequently probed to recall which letter appeared in a specific position in the sequence. Schizophrenic patients' recall is disproportionately worse than that of control participants for items that need to be maintained for longer periods (i.e., those presented earlier in the list; Elvevåg, Fisher, \& Goldberg, 2003). Results such as these have generally been interpreted within a framework of impaired information maintenance in memory, such that in conditions with longer sequences or long time intervals, the deficit in schizophrenia becomes more apparent.

The second line of research of relevance here concerns data that demonstrate impaired timing abilities over durations similar to those used in the above-mentioned working memory experiments (i.e., of seconds or less; e.g., Lhamon \& Goldstone, 1956; Rammsayer, 1990; Tracy et al., 1998; Tysk, 1983; Volz et al., 2001; but see Webster, Goldstone, \& Webb, 1962). Our recent exploration of duration identification in schizophrenia used auditory tasks in which a standard interval (in a temporal generalization task) or intervals (in a temporal bisection task) were presented in an exposure phase at the beginning of the task and assumed to be held in memory for subsequent comparison with test stimuli. We found 
that patients with schizophrenia were less accurate at estimating brief time periods (Elvevåg, McCormack, Gilbert, Brown, \& Weinberger, 2003). Deficits such as these have been taken to suggest a dysfunction of biopsychological timing. There have been recent theoretical suggestions that timing ability and working memory may be closely connected (e.g., Brown \& Chater, 2001; Brown, Neath, \& Chater, 2002; Brown, Preece, \& Hulme, 2000; Burgess \& Hitch, 1992, 1999; Church \& Broadbent, 1990; Gallistel, 1990; Gallistel \& Gibbon, 2000), and one aim of the present article is to connect this second line of research with the first by examining whether equivalent memory and timing deficits can be found in comparable tasks. Evidence for a theoretical association between timing difficulties and memory deficits would be strengthened if timing and memory deficits are both observed while at the same time no deficit is observed on a comparable task involving identification of line lengths; we address this question experimentally.

A third line of research of interest here concerns the identification and classification of stimuli that vary along dimensions other than duration. In absolute identification tasks, participants must identify stimuli in terms of their position in a previously presented series of stimuli that vary along the relevant dimension. In these tasks, participants match stimuli to an absolute template and, thus, these tasks are different from a "magnitude estimation" task in which one explicitly makes relative judgments. Absolute identification tasks also differ from low-level perceptual discrimination tasks in that the stimuli to be identified are normally assumed to be perceptually discriminable when presented pairwise. Identification tasks of this type have not been used widely in studies of schizophrenia, and one purpose of the present study is to extend such studies to this population. However, there is some evidence that schizophrenia is associated with impaired low-level perceptual discrimination ability, even when items cannot be encoded verbally. For example, a recent study of weight discrimination of items between 275 and 350 grams found that schizophrenic patients required a larger difference between weights than did control participants to obtain over $80 \%$ correct detection (Javitt, Liederman, Cienfuegos, \& Shelley, 1999). It is interesting to note that patients' discrimination accuracy following a 5-s or a 30-s delay displayed the same progressive decay in accuracy as did that of control participants, thus suggesting that the deficit reflects imprecision in processing rather than a memory requirement of the task. Javitt and colleagues have similar findings from a tone discrimination task in patients with schizophrenia (Javitt, Strous, Grochowski, Ritter, \& Cowan, 1997; Javitt et al., 1999), with patients showing a high level of impairment in pitch discrimination ability, and it is important to note that this is not due to any group difference in maintaining the memory trace over variable intervals (Javitt et al., 1997, 1999).

Research in these three separate fields (working memory, timing estimation, and absolute identification) has generally been conducted independently. In cognitive psychology, there is a growing interest in exploring the relationship between time and the temporal organization of episodic memory (e.g., Hoerl \& McCormack, 2001). For example, some recent models of serial order memory (e.g., Brown et al., 2000; Burgess \& Hitch, 1999) make the assumption that items are coded in memory in terms of their position along a temporal continuum, while others assume items are represented in terms of their temporal distance from the present (e.g., Brown \& Chater, 2001; Brown et al., 2002). This line of research suggests attempts to find similarities among cognitive tasks, and ultimately processes, by designing tasks that are structurally comparable (Brown \& Chater, 2001). For example, the probed-recall task described above may be regarded as structurally similar to an absolute identification task in the sense that participants must judge stimuli in terms of their position along a dimension in both tasks (Brown et al., 2002). In absolute identification, the dimension may be, for example, line length, weight, brightness, loudness, or duration; in probed serial recall, the dimension is temporal distance from the present. To adopt Crowder's (1976) analogy, discriminating items from a list (from the temporal perspective of the end of the list as in probed serial recall) may be analogous to viewing a row of evenly spaced telegraph poles from the end of the row. Temporally distant items may be hard to discriminate in memory for the same reason (Weberian compression) that spatially distant telegraph poles are more confusable than near telegraph poles (see Brown et al., 2002, for extensive discussion).

In the current study, we examined tone-duration identification, line-length identification, and probed-recall memory performance in schizophrenia within a comparable experimental framework. We can express the main theoretical concern of the present article in terms of two hypotheses that make contrasting predictions for performance on the different tasks. If patients with schizophrenia suffer from a global impairment in absolute identification, they will show deficits on all three tasks. We refer to this as the global identification deficit hypothesis. If, on the other hand, the patient group is selectively impaired in performance on the timing and probed-recall task but relatively unimpaired on the identification of line length, support may be gained for the idea that a common deficit underlies schizophrenia-related impairment on timing and probed-recall tasks (which, according to some theoretical accounts, may both involve temporal processing). We call this the temporal deficit hypothesis.

More generally, our experimental approach enables examination of similarities in processes that have traditionally been regarded as different. Moreover, experiments of this type yield rich error data that can be used to explore the nature of qualitative and quantitative differences in performances between patients and healthy control participants. Such information can be valuable in constraining theories concerning cognitive deficits in schizophrenia; such an approach is much needed (e.g., Elvevåg, Weinberger, \& Goldberg, 2001).

Research on absolute identification has shown that when items must be identified in terms of their position along a single psychophysical dimension, serial position effects typically occur (e.g., Berliner, Durlach, \& Braida, 1977; Brown et al., 2002; Lacouture, 1997; Luce, Green, \& Weber, 1976; Luce, Nosofsky, Green, \& Smith, 1982; Murdock, 1960). Thus, graphs of correct performance plotted as a function of stimulus serial position are generally $U$-shaped, with better performance at the beginning and end of the stimuli series. This may be because items near the ends are more "distinctive" (i.e., they have fewer close neighbors: Brown et al., 2002; Murdock, 1960). A key question addressed by the current study was whether deficits that are observed in patients with schizophrenia on identification tasks, such as stimulusduration identification, would also be seen on tasks that involve judging stimuli that vary along other dimensions. The use of tasks that involve stimulus dimensions other than duration permits examination of whether any impairments in schizophrenia observed in these absolute identification tasks are likely to be due to pri- 
marily global impairments in stimulus identification or whether there are deficits specific to timing, size identification, and/or working memory. Thus, in the current study, we used three tasks: a tone-duration identification task, a line-length identification task, and a probed recall task.

\section{General Methodology}

\section{Participants and Baseline Tests}

In- and outpatients from the National Institute of Mental Health research wards participated in this study. All patients fulfilled Diagnostic and Statistical Manual of Mental Disorders (DSM-IV; American Psychiatric Association, 1994) criteria for schizophrenia, as determined by the Structured Clinical Interview for DSM-IV (SCID), with three psychiatrists reaching a consensus diagnosis. Patients generally had multiple hospital admissions because of incomplete responses to conventional treatments. Control volunteers were recruited through the National Institutes of Health volunteer panel. No participant, control or patient, with a history of traumatic brain injury, epilepsy, developmental disorder, diagnosable current substance dependence, or other known neurological condition was included in this study. All participants had normal or normal corrected vision, and the presence of normal hearing ability was established using standard clinical procedures. All control participants were paid for their participation. This study was approved by the internal review board at the National Institute of Mental Health, and informed consent was obtained from all participants prior to testing.

Table 1 shows the mean ages and background test scores of the patients and control participants who participated in all three experiments as well as the medication details for the patients. The order of task presentation was as follows: tone identification, line-length identification, and probed recall

Table 1

Characteristics of Patient and Control Samples

\begin{tabular}{|c|c|c|c|c|}
\hline \multirow[b]{2}{*}{ Measure } & \multicolumn{2}{|c|}{$\begin{array}{l}\text { Patients } \\
(n=20)^{\mathrm{a}}\end{array}$} & \multicolumn{2}{|c|}{$\begin{array}{c}\text { Control } \\
\text { participants } \\
(n=20)^{\mathrm{b}}\end{array}$} \\
\hline & $M$ & $S D$ & $M$ & $S D$ \\
\hline Age (years) & 37.4 & 8.4 & 35.9 & 7.7 \\
\hline WRAT-R IQ & 101.4 & 11.5 & 104.8 & 9.4 \\
\hline WAIS-R IQ* & 92.1 & 9.3 & 105.2 & 10.3 \\
\hline Cattell IQ* & 94.4 & 17.8 & 106.8 & 16.7 \\
\hline Digit Span: total* & 14.4 & 2.8 & 17.9 & 4.2 \\
\hline Forward only* & 7.7 & 1.6 & 9.1 & 2.3 \\
\hline Backward only* & 6.7 & 2.0 & 8.9 & 2.5 \\
\hline Age at 1 st hospitalization (years) & 21.2 & 5.4 & & \\
\hline Years since 1 st hospitalization & 16.2 & 8.7 & \multirow{2}{*}{\multicolumn{2}{|c|}{$n=0$}} \\
\hline Neuroleptic medication & \multicolumn{2}{|c|}{$n=19^{0.1}$} & & \\
\hline Clozapine & \multicolumn{2}{|c|}{$6(250-550 \mathrm{mg})$} & & \\
\hline Olanzapine & \multicolumn{2}{|c|}{$7(15-30 \mathrm{mg})$} & & \\
\hline Risperidone & \multicolumn{2}{|c|}{$5(1-6 \mathrm{mg})$} & & \\
\hline High potency drugs $^{c}$ & \multicolumn{2}{|c|}{$2(4-15 \mathrm{mg})$} & & \\
\hline Anticholinergics & \multicolumn{2}{|c|}{1} & & \\
\hline Adjunctives ${ }^{\mathrm{d}}$ & \multicolumn{2}{|l|}{13} & & \\
\hline
\end{tabular}

Note. There was no significant difference between inpatients and outpatients in terms of age, Wechsler Adult Intelligence Scale-Revised (WAIS-R), Wide Range Achievement Test-Revised (WRAT-R), Cattell, Digit Span (total, forwards, or backwards), age at first hospitalization, and the number of years since first hospitalization (in all cases, $p>.05$; independent samples $t$ tests).

${ }^{a}$ Eight inpatients, 12 outpatients; 17 men, 3 women. ${ }^{\mathrm{b}}$ Fourteen men, 6 women. ${ }^{\mathrm{c}}$ Haloperidol, fluphenazine, and loxapine. ${ }^{\mathrm{d}}$ Lithium, depakote, sertraline, lorazepam, venlafaxine, clonazepam, and buspirone. $* p<.05$ (independent samples $t$ test). for half of the participants, and probed recall, line-length identification, and tone identification for the other half of the participants (i.e., counterbalanced within the patient and control group). Three baseline tests were used to index intellectual function. The first was a test of reading proficiency, the Wide Range Achievement Test-Revised (WRAT-R; Jastak \& Wilkinson, 1984), which is widely used as a putative measure of premorbid intellectual functioning (Goldberg et al., 1995; Kremen et al., 1996; Wiens, Bryan, \& Crossen, 1993). The second was a short version of the Wechsler Adult Intelligence Scale-Revised (WAIS-R; Wechsler, 1981; see also, Kaufman, 1990; Missar, Gold, \& Goldberg, 1994). The third was a standard test of current nonverbal or fluid intelligence, Cattell's Culture Fair Intelligence Test (Cattell, 1971; Institute for Personality and Ability Testing, 1973), Scale 2, Form A. The test involves timed nonverbal problemsolving. The substantial drop in intelligence from estimated premorbid function that we observed is often reported in schizophrenia (Weickert et al., 2000). Digit Span was assessed using the Wechsler Memory ScaleRevised (Wechsler, 1987).

\section{Experiment 1: Tone-Duration Identification Task}

In this experiment, participants were presented with a series of seven tones that varied solely in duration. The task was to identify the tones in terms of their serial position in the series. In control participants, we expected that correct performance as a function of stimulus serial position would follow a $U$-shaped function, with better accuracy for stimuli at the beginning and end of the series. Performance of patients with schizophrenia was compared with that of control participants. Both the temporal deficit hypothesis and the global identification hypothesis predict an impairment in the patient group; examination of detailed error patterns may enable more detailed qualitative differences in performance to be identified.

\section{Method}

Design and procedure. Tones were presented using SuperLab 1.68 (1994) experiment scripting software. Tones were generated with Sndsampler (2000) software, using the tone-generator function. All tones were 16-bit, mono, $100 \%$ amplitude sine waves, $1000 \mathrm{~Hz}$ frequency, with a 32 $\mathrm{kHz}$ sample rate. The tones were not ramped (i.e., no rise and fall time). The tones were presented by means of a computer and ranged in duration from a third of a second to two and a third seconds. Thus, the tones were $333,667,1,000,1,333,1,667,2,000$, and 2,333 ms in duration. Each tone was given a label of 1-7, with 1 being the shortest and 7 the longest tone. At the beginning of the experiment, all experimental stimuli in the set were presented twice, with their associated labels, to ensure that participants were familiar with the seven different tones and their labels. In the actual experiment, participants were presented with one stimulus at a time and were asked to say the label learned in the training phase, even if they were unsure. After each decision had been made, feedback as to the correct answer was presented on the computer screen (e.g., "That was tone N"). In the main part of the experiment, there were three blocks of 84 trials (thus comprising 36 data points per tone).

\section{Results}

Figure 1 shows the proportion of correct responses for each tone number. It can be seen that patients performed less accurately than control participants. An analysis of variance (ANOVA) on correct performance was conducted with group (control participants, patients) as the between-subjects variable and tone number (1-7) as the within-subjects variable. The main effect of group was significant, $F(1,38)=14.66, p<.001$, and the effect of tone number was significant, $F(6,228)=83.96, p<.0001$. The interaction 


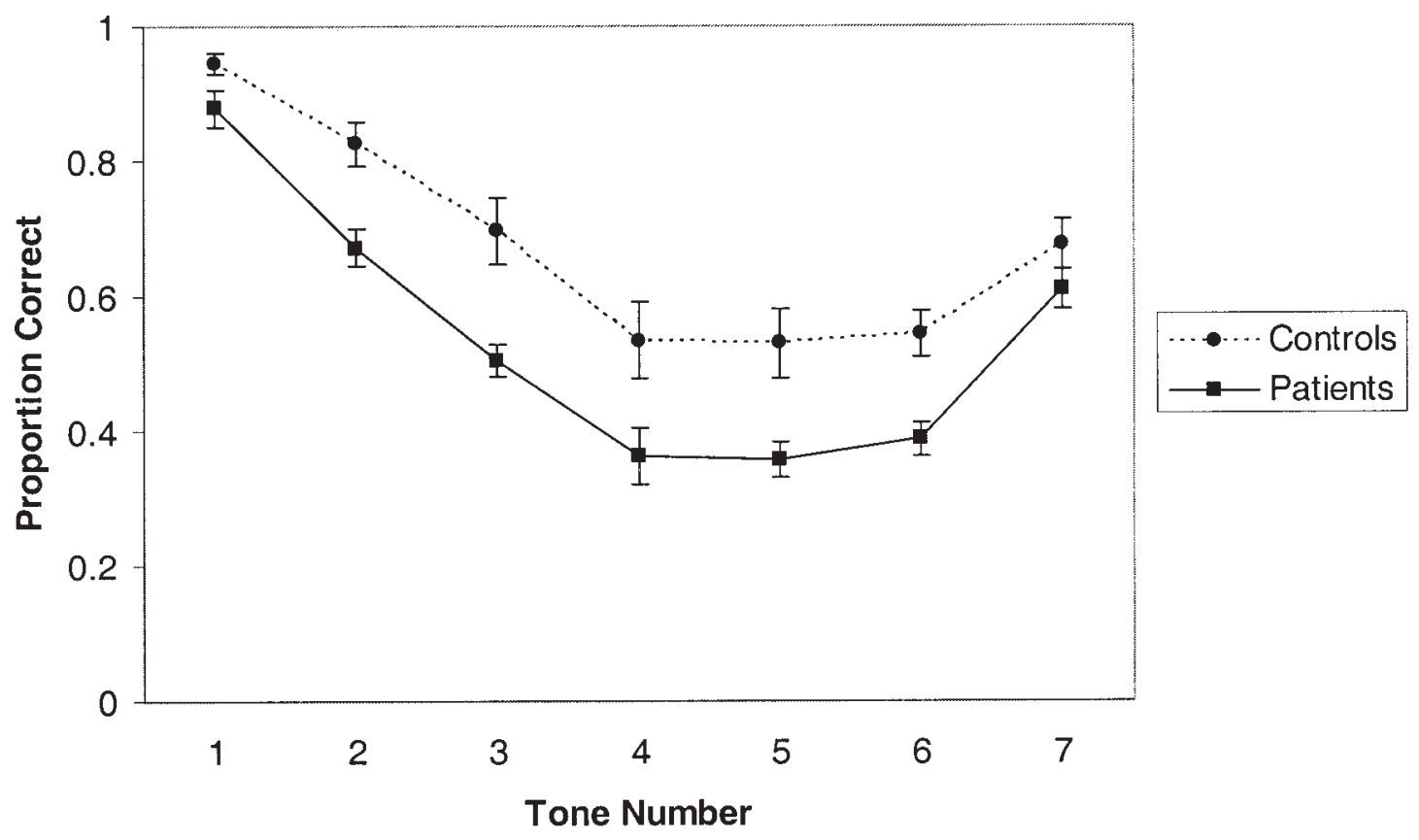

Figure 1. Proportion of correct responses as a function of tone response number in Experiment 1. Standard error bars of the mean are shown.

between group and tone number was not significant, $F(6,228)=$ $1.81, n s$.

We then analyzed responses in more detail, such that we could examine the distribution of responses given to each tone (see Figure 2). Thus, for each tone (e.g., Tone 1), the proportions of responses that were made for the correct tone (e.g., Tone 1) versus all others (e.g., Tones 2-6) were plotted. It is clear that the response gradients peak at the correct value (e.g., most responses for Tone Response 1 were correct and thus responses for Tone 1 peak) and decline with the distance from the correct value. Group differences in the steepness of response error gradients were examined by calculating for each participant the proportion of error responses that were one response number away from the correct value. For the patients, the mean proportion of errors of this type was $.81(S D=.09)$, and for control participants, the value was .83 $(S D=.13)$. A $t$ test for independent samples on these data showed that there was no significant difference between the groups in terms of the proportions of error responses that were just one response number away from the correct value, $t(38)=-0.41, n s$. It is noteworthy that the response gradients' asymptote closes to zero (e.g., Response 7 was virtually never given when Tone 1 was the stimulus and vice versa). This indicates that there was no significant level of guessing or random responding and that participants did not have problems with learning the stimulus labels. Additional evidence is given by the absence of differential learning effects for patients and control participants. For the control participants, performance on the first 50 trials was $66 \%$ correct, and performance on the last 50 trials was $66 \%$. For patients, the equivalent figures are $53 \%$ and $51 \%$. Thus, there was little learning overall, consistent with previous results (e.g., Shiffrin \& Nosofsky, 1994), and the patient deficit cannot be explained by slower learning of the task.

Finally, we examined whether the average response given to each tone differed between the groups. Figure 2 shows that the response gradients are typically symmetrical, with error responses being approximately evenly distributed between numbers greater and smaller than the tone's actual value. Previous studies of other populations (young children and older adults) have sometimes found asymmetries in such gradients and have taken such asymmetries as evidence for systematic distortions in the memory representations of the stimuli (e.g., Droit-Volet, Clement, \& Wearden, 2001; McCormack, Brown, Maylor, Darby, \& Green, 1999; McCormack, Brown, Maylor, Richardson, \& Darby, 2002). Therefore, we analyzed the symmetry of responses in more detail. It is clear from Figure 2 that the average response to each tone is generally close to the tone's true value: Participants showed no consistent tendency to either underestimate or overestimate the value of the tones. An ANOVA of these data with group (control participants, patients) as the between-subjects variable and tone number (1-7) as the within-subjects variable found that there was no significant main effect of group, $F(1,38)=0.34, n s$. There was a significant main effect of tone number, $F(6,228)=1,463.38$ $p<.0001$. The Group $\times$ Tone Number interaction approached significance at the conventional level, $F(6,228)=2.13, p=.05$. However, post hoc $t$ tests for each tone number comparing patients and control participants when corrected for multiple tests of comparison (using a modified Bonferroni method; Holm's, 1979, sequentially rejective procedure) did not reveal any significant group differences.

\section{Discussion}

The main finding in Experiment 1 was that patients' performance on the duration-identification task was less accurate than that of control participants. It is important to note that when we examined the nature of errors that participants made, we found that the groups were qualitatively comparable. It is interesting that this duration-identification task resulted in serial position curves and 


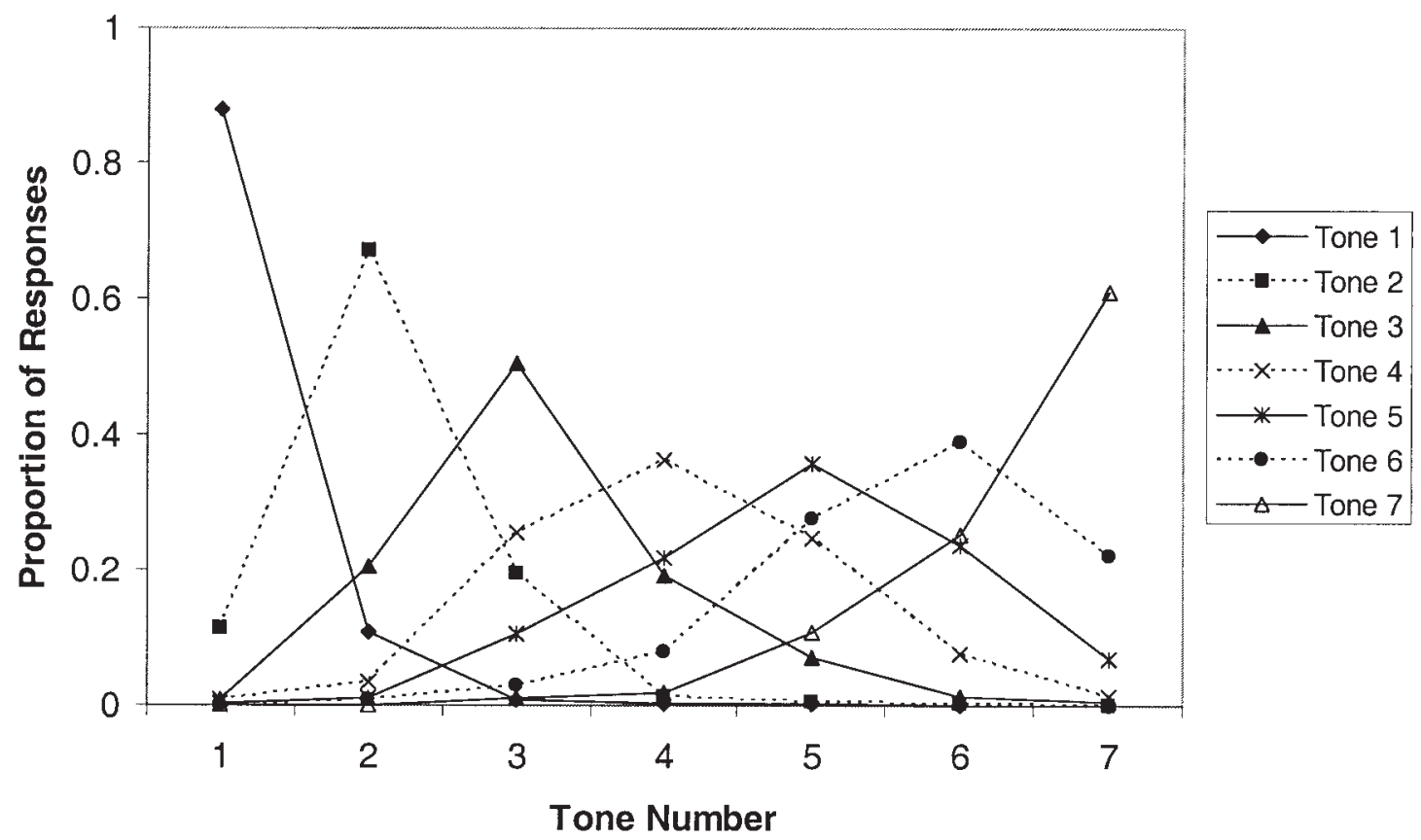

$\mathrm{B}$

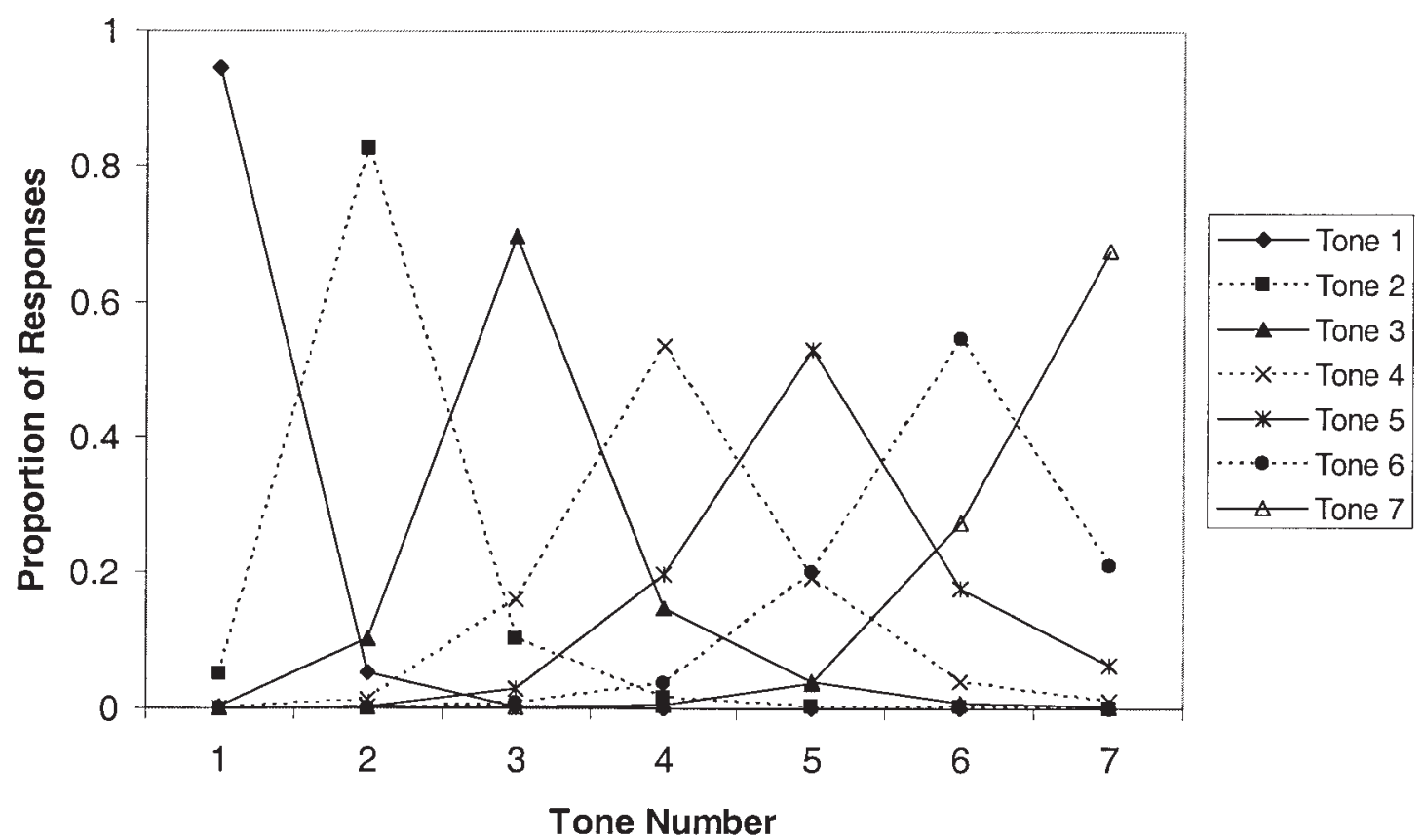

Figure 2. Response gradients as a function of tone response number in Experiment 1 for patients (A) and control participants (B).

response gradients that have been observed in tasks with other stimulus dimensions. For example, in a previous study in which we examined short-term memory for serial order in patients with schizophrenia (as compared with control participants), we ob- served very similar response profiles and a lack of a group difference in terms of response gradients (Elvevåg, Weinberger, \& Goldberg, 2001), in which transposition gradients were similar in patients and control participants (unpublished observations). In 
Experiment 2, we explored the extent to which patients' performance profile is comparable in another absolute identification task, which, although structurally similar, does not involve duration identifications. This allows us to address the question of whether the performance deficit is specific to the temporal domain.

\section{Experiment 2: Line-Length Identification Task}

The line-length identification task was also presented using SuperLab 1.68 software (1994). In this experiment, participants were presented with a series of seven lines that varied in length. The task was to identify the lines in terms of their serial position within the series. In control participants, we expected that correct performance as a function of stimulus serial position would follow the U-shaped function that we observed in Experiment 1, with better accuracy for stimuli at the beginning and end of the series. Performance of patients with schizophrenia was compared with that of healthy control participants. The global identification hypothesis predicts an impairment in the patient group; the temporal deficit hypothesis in contrast predicts that patients' performance will be unimpaired relative to the deficit seen in Experiment 1. As in Experiment 1, examination of detailed error patterns may enable more detailed qualitative differences in performance to be identified.

\section{Method}

Design and procedure. The lines ranged from $1 \mathrm{~cm}$ in length to $7 \mathrm{~cm}$ in length, such that the lines were of the lengths $1,2,3,4,5,6$, and $7 \mathrm{~cm}$. Each line was given a label of 1-7, with 1 being the shortest and 7 the longest line. As in Experiment 1, at the beginning of the experiment, all experimental stimuli in the set were presented twice, with their associated labels, to ensure that participants were familiar with the seven different lines and their labels. In the actual experiment, participants were presented with one stimulus at a time and asked to say the label learned in the training phase. Participants were required to give a response, even if they were unsure. After each decision had been made, feedback was given by means of the computer monitor as to what length the line was (e.g., "That was line N"). In the main part of the experiment, there were 70 trials presented in pseudorandom order (and thus 10 data points per line length). Each line was presented for $400 \mathrm{~ms}$.

\section{Results}

Figure 3 shows the proportion of correct responses for each line length. It can be seen that the performance accuracy of patients and control participants was very similar. An ANOVA of correct performance was conducted with group (control participants, patients) as the between-subjects variable and line length (1-7) as the within-subjects variable. There was no main effect of group, $F(1$, $38)=0.07, n s$. There was a significant main effect of line length, $F(6,228)=30.21, p<.0001$. The interaction between group and line length was not significant, $F(6,228)=1.02$, ns.

We then analyzed responses in more detail, such that we could examine the distribution of responses given to each line (see Figure 4). As in Experiment 1, for each line length (e.g., Line 1), the proportions of responses that were correct for the actual line length (e.g., Line 1) versus all the others (e.g., Lines 2-6) were plotted. It is clear that the response gradients peak at the correct value (e.g., most responses for Line Length 1 were actually correct and thus responses for Line Length 1 peak at this number) and decline with the distance from the correct value. Group differences in the steepness of response gradients were examined by calculating for each participant the proportion of error responses that were one response number away from the correct value. For the patients, the mean proportion of errors of this type was $.77(S D=.11)$, and for control participants, the value was also $.77(S D=.12)$. A $t$ test

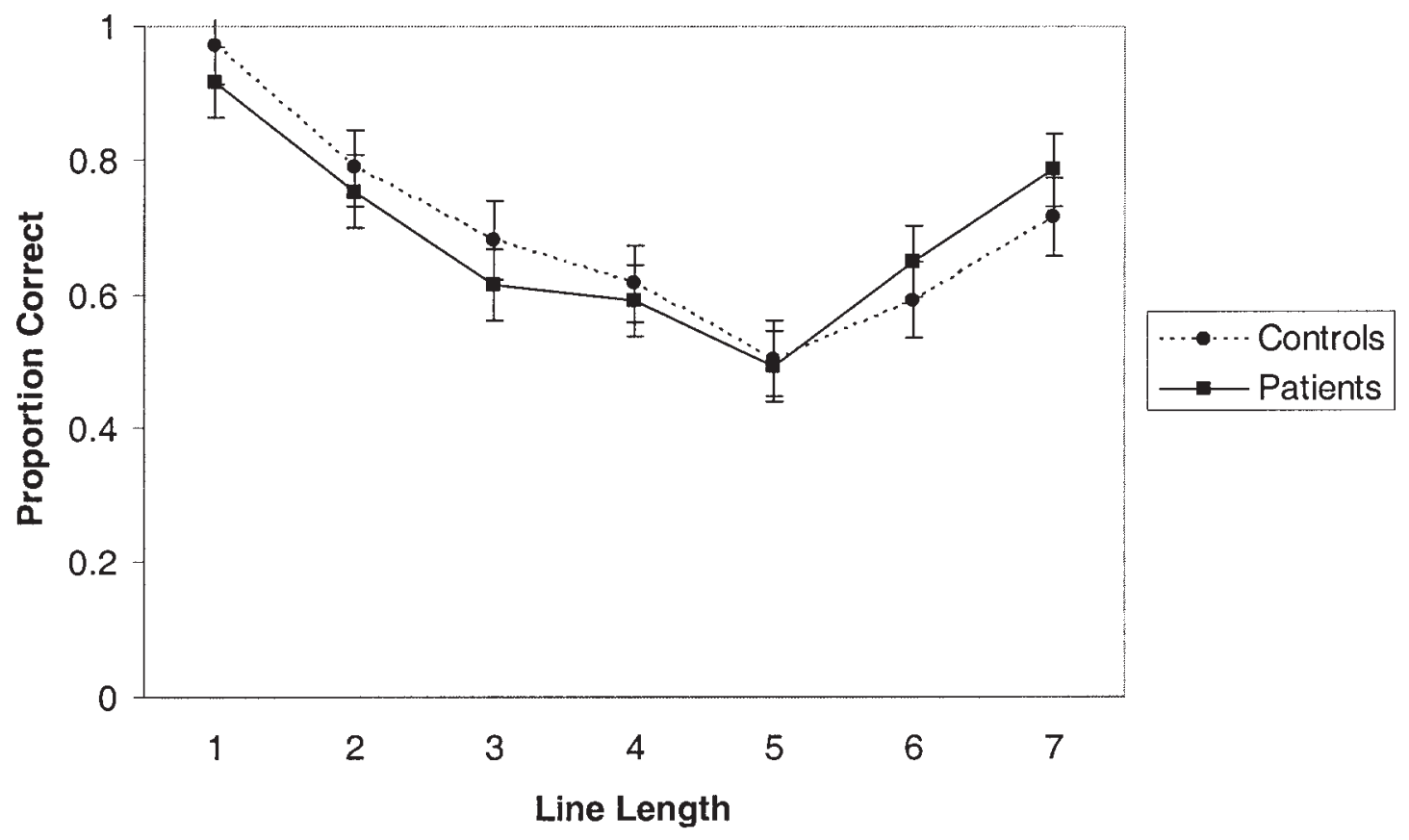

Figure 3. Proportion of correct responses as a function of line-length response number in Experiment 2. Standard error bars of the mean are shown. 


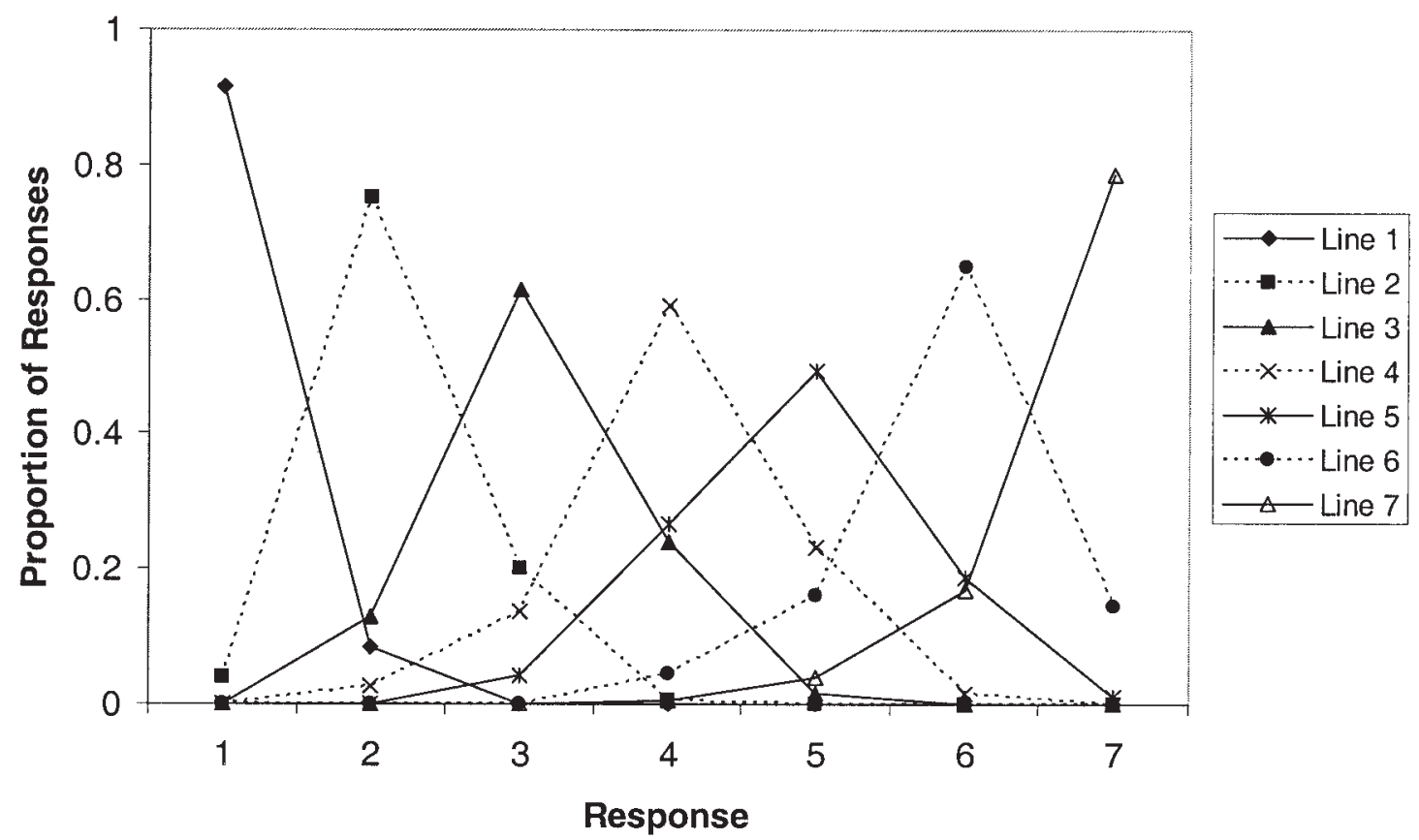

B

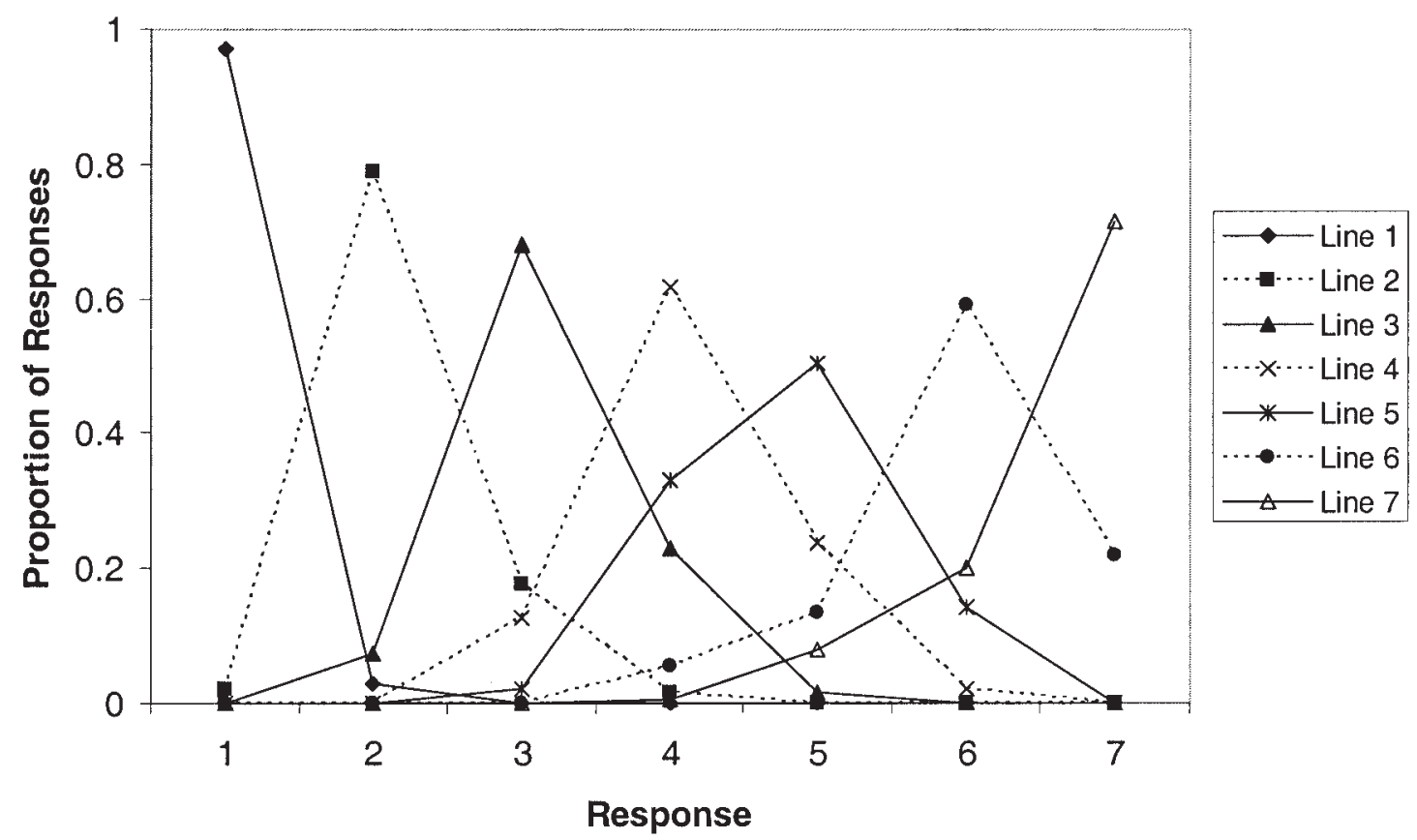

Figure 4. Response gradients as a function of line-length response number in Experiment 2 for patients (A) and controls (B).

for independent samples on these data showed that there was no significant difference between the groups in terms of the proportions of error responses that were just one response number away from the correct value, $t(38)=0.07, n s$.
Finally, we examined whether the average response given to each line length differed between the groups. With reference to Figure 4, it would appear that the response gradients are typically symmetrical, with error responses being approximately evenly 
distributed between numbers greater and smaller than the line's actual length. It is clear from Figure 4 that the average response to each line length is generally close to the line's true length: Participants show no consistent tendency to either underestimate or overestimate the length of the lines. An ANOVA of these data with group (control participants, patients) as the between-subjects variable and line length (1-7) as the within-subjects variable found that there was no significant main effect of group, $F(1,38)=0.01$, $n s$. There was a significant main effect of line length, $F(6,228)=$ $2,891.01, p<.0001$, but there was no significant Group $\times$ Line Length interaction, $F(6,228)=1.10$, ns.

\section{Discussion}

The main finding in Experiment 2 was that patients' performance on the line-length identification task was comparable to that of control participants. Moreover, when we examined the nature of errors that participants made, we found that the groups were qualitatively similar. As in Experiment 1, the lack of a group difference in response gradients is similar to previous findings we have observed in a serial recall task. Task difficulty issues alone cannot account for the absence of a group difference in this task combined with the clear group difference in Experiment 1, because the level of performance of the control group was roughly similar in each case. The issue of task-discriminating power is addressed in later analyses, but, to anticipate, task-discriminating power (as assessed by true score variance) was identical for Experiments 1 and 2 , consistent with the suggestion that the reduced performance on duration identification reflects a true differential deficit. Moreover, the line-length identification task resulted in serial position curves and response gradients that have been observed in tasks with other stimulus dimensions (such as tone-duration identification in Experiment 1). We now turn to an examination of patients' performance on a memory task using a similar methodology to that used in the previous experiments.

\section{Experiment 3: Probed-Recall Task}

Experiment 3 was a probed serial recall task. In the probed serial recall task, participants are presented with a temporal sequence of seven letters (e.g., $A B C D E F G$ ). Immediately after presentation of the last item, a single item from the list (e.g., $C$ ) is presented, and participants must respond with the position of that item within the presented sequence (e.g., 3). Thus, the task is a memory task that can be viewed as analogous to the identification tasks of Experiments 1 and 2, in that responses to test items must be based on their positions along a continuous dimension. In probed serial recall, the continuous dimension is positional or temporal. As in Experiments 1 and 2, we expected that correct performance as a function of stimulus serial position would follow a U-shaped curve, with primacy and recency effects. Performance of patients with schizophrenia was compared with that of healthy control participants.

If, as suggested by the temporal deficit hypothesis, common mechanisms may underpin performance on both timing and probed serial recall tasks, the patient group should show performance that is impaired to an extent approximately equivalent to that observed in Experiment 1.

\section{Method}

Design and procedure. Using SuperLab 1.68 experiment software (1994), the letters in each sequence were presented on a computer screen at a rate of one every $333 \mathrm{~ms}$. There were no interitem gaps; each item was displayed for $333 \mathrm{~ms}$. Thus, at the time of test, the temporal distances of the letters were the same as the durations used as stimuli in Experiment 1. After presentation of the last item, a probe letter appeared. The task was to recall the serial position in which the probe letter had appeared. At the beginning of the experiment, each probe position in the set was presented twice, so as to ensure that participants were familiar with the task. Participants were required to give a response, even if they were unsure. After each decision had been made, feedback was given on the computer screen as to what the correct answer was (e.g., "That was the $n$th position"). Thus, unlike Experiments 1 and 2 in which participants were presented with one stimulus at a time and asked to say the label learned in the training phase, here in Experiment 3, participants were presented with a series of letters and then a probe and were asked to state the position in which the probe appeared (e.g., first, third, last, etc.). In the main part of the experiment, there were three blocks of 84 trials (thus comprising 36 data points per serial position).

\section{Results}

Figure 5 shows the proportion of correct responses for each probe position. It can be seen that patients performed less accurately than control participants. An ANOVA on correct performance was conducted with group (control participants, patients) as the between-subjects variable and probe position (1-7) as the within-subjects variable. There was a main effect of group, $F(1$, $38)=8.22, p<.01$, and a significant effect of probe position, $F(6$, $228)=16.78, p<.0001$. The interaction between group and probe position was not significant, $F(6,228)=0.57$, $n s$.

We then analyzed responses in greater detail, such that we could examine the distribution of responses given to each probe position (see Figure 6). As in Experiments 1 and 2, for each probe position (e.g., Position 1), the proportions of responses that were for the correct probe position (e.g., Probe Position 1) versus all others (e.g., Probe Positions 2-6) were plotted. It is clear that the response gradients peak at the correct value (e.g., most responses for Probe Response Position 1 were actually correct, and, thus, responses for Probe Response Position 1 peak at this number) and decline with the distance from the correct value. Group differences in the steepness of response gradients were examined by calculating for each participant the proportions of error responses that were one response number away from the correct value. For the patients, the mean proportion of errors of this type was $.44(S D=$ .07 ), and, for control participants, the value was also .54 ( $S D=$ .09). A $t$ test for independent samples on these data showed that there was a significant difference between the groups in terms of the proportions of error responses that were just one number away from the correct value, $t(38)=-3.91, p<.001$. In other words, patients' response gradients were less steep than control participants'.

Finally, we examined whether the average response given to each probe position differed between the groups. The response gradients are typically symmetrical, with error responses being approximately evenly distributed between probe positions greater and smaller than the actual probed position. It is clear from Figure 6 that the average response to each probe position is generally close to the probe position's true value: Participants show no consistent tendency to either underestimate or overesti- 


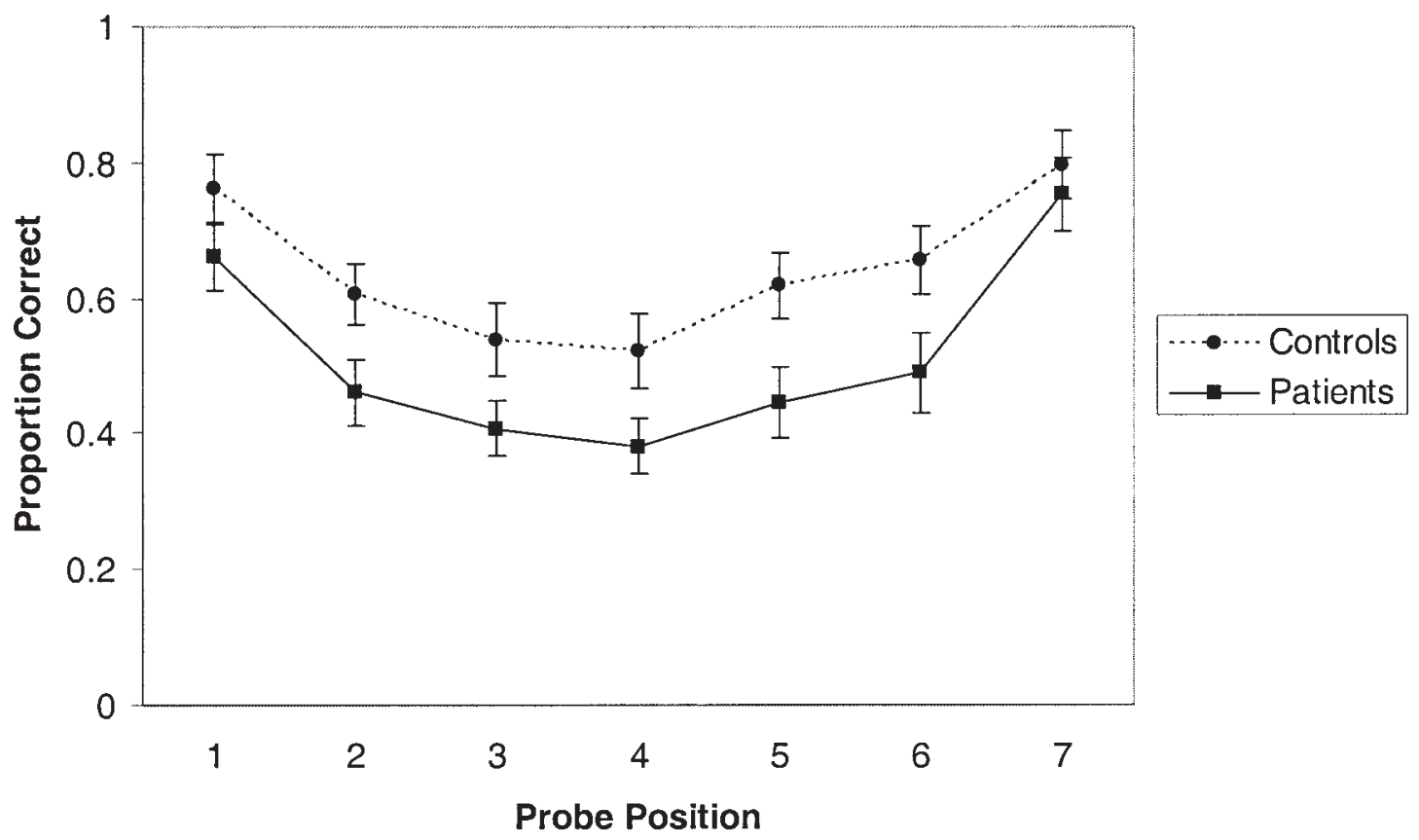

Figure 5. Proportion of correct responses as a function of probe position response number in Experiment 3. Standard error bars of the mean are shown.

mate the position of the probe. An ANOVA of these data with group (control participants, patients) as the between-subjects variable and probe position (1-7) as the within-subjects variable found that there was no significant main effect of group, $F(1,38)=0.92$, $n s$. There was a significant main effect of probe position, $F(6$, $228)=556.30, p<.0001$, and there was a significant Group $\times$ Probe Position interaction, $F(6,228)=6.21, p<.0001)$. This reflected a small tendency for patients to respond with positions toward the middle of the list, namely, to underestimate the position of late presented items and overestimate the position of early presented items. Such an effect is common in memory and identification tasks (e.g., Stewart, Brown, \& Chater, 2002; Underwood, 1977) and may represent a central tendency in guessing when information is lacking (James \& Stein, 1961; Johnson, 1952).

\section{Discussion}

The main finding of Experiment 3 was that patients with schizophrenia were significantly impaired on the probed serial recall task, as in the duration-identification task (Experiment 1) but in clear contrast to the line-length identification task (Experiment 2). The magnitude of impairment in Experiment 3 was roughly comparable to that found in Experiment 1. We discuss the theoretical significance of the overall pattern of results below.

A minor point of contrast between Experiment 3 and Experiments 1 and 2 concerned the nature of the error gradients. Error gradients were more shallow for patients with schizophrenia in Experiment 3 only. Examination of Figure 6 reveals that large errors are more likely in the probed-recall task than in Experiments 1 and 2, and this is why the error gradients are more shallow. The greater probability of relatively long distance errors in Experiment 3 probably reflects the nature of the task. If encoding fails during presentation in the probed-recall task, participants can only guess at the position of a test item that was not encoded, and under such conditions, there is no reason for incorrect responses to be close to the correct response.

\section{Direct Comparison Across All Three Experimental Tasks}

Further cross-task statistical analyses were carried out to examine the specificity of the deficit shown by the patients. A cross-task ANOVA (Experiments 1, 2, and 3) was carried out on overall performance. There was a significant Group $\times$ Task interaction, $F(2,76)=6.12, p<.01$, reflecting an impairment of the patient group on the duration-identification task and on the probed-recall task but not on the line-length identification task. It seems unlikely that our results (in patients) can be attributed to differential deficits arising from differences in task difficulty. This is because whereas overall performance for control participants was $68 \%$ for Experiment 1, 70\% for Experiment 2, and 64\% for Experiment 3, the difference in level of performance within each experiment as a function of serial position was much greater. Thus, for example, in Experiment 2, there was no deficit even for the serial positions where performance was at or below about $60 \%$. However, the ability of a task to detect a between-group difference is not necessarily a function of task difficulty per se. We therefore undertook power analyses to determine whether the lineidentification task (in which no difference between patients and control participants was observed) would likely have been able to detect a between-group difference of the magnitude observed in the duration-identification task. These analyses confirmed that the line-identification task would have been likely to detect such an effect. More specifically, the line-identification task had a power of .97 to detect a between-group difference of the magnitude observed in duration identification and a power of .96 to detect an equivalent effect size (Cohen's $f=.61$ ). It is therefore unlikely 


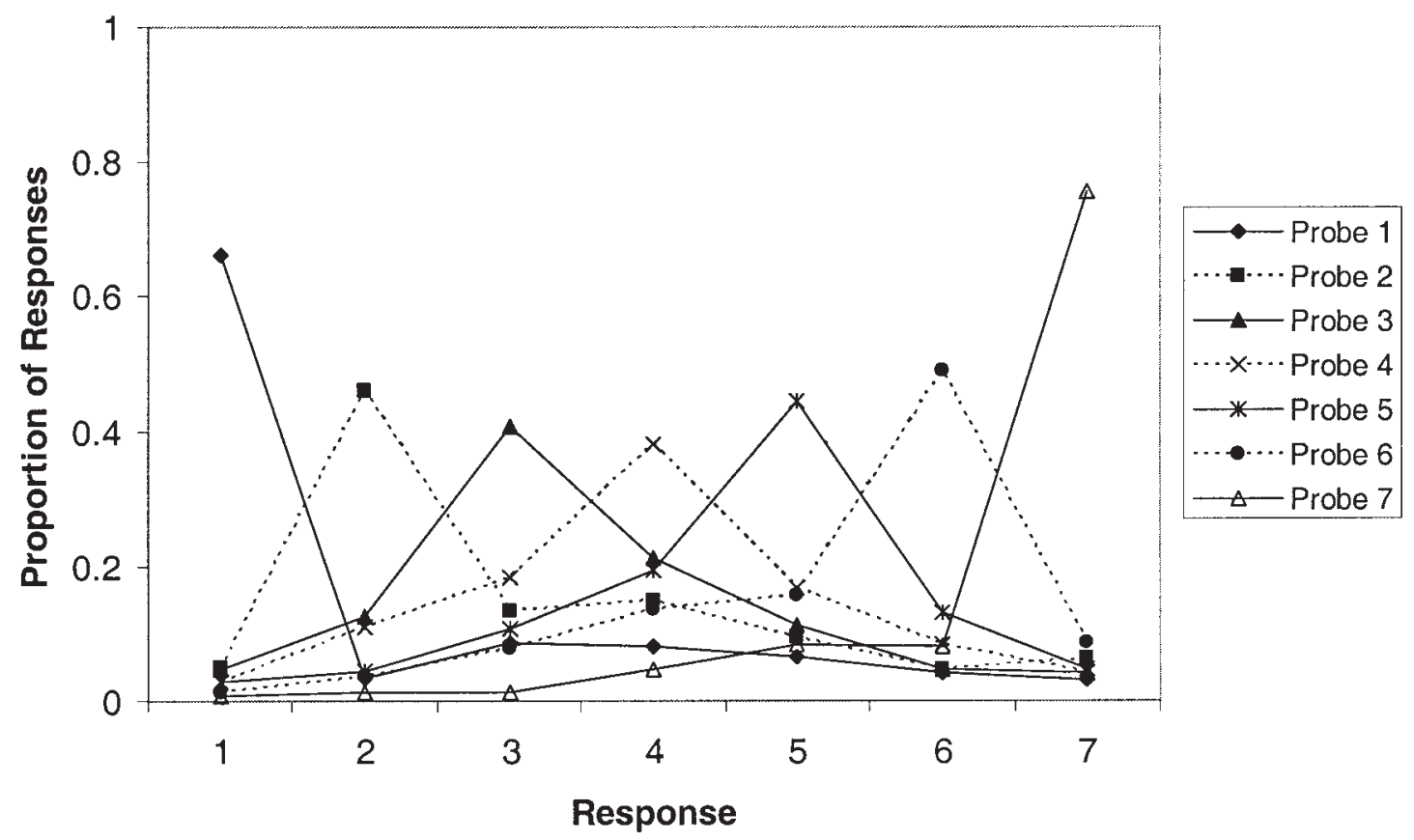

B

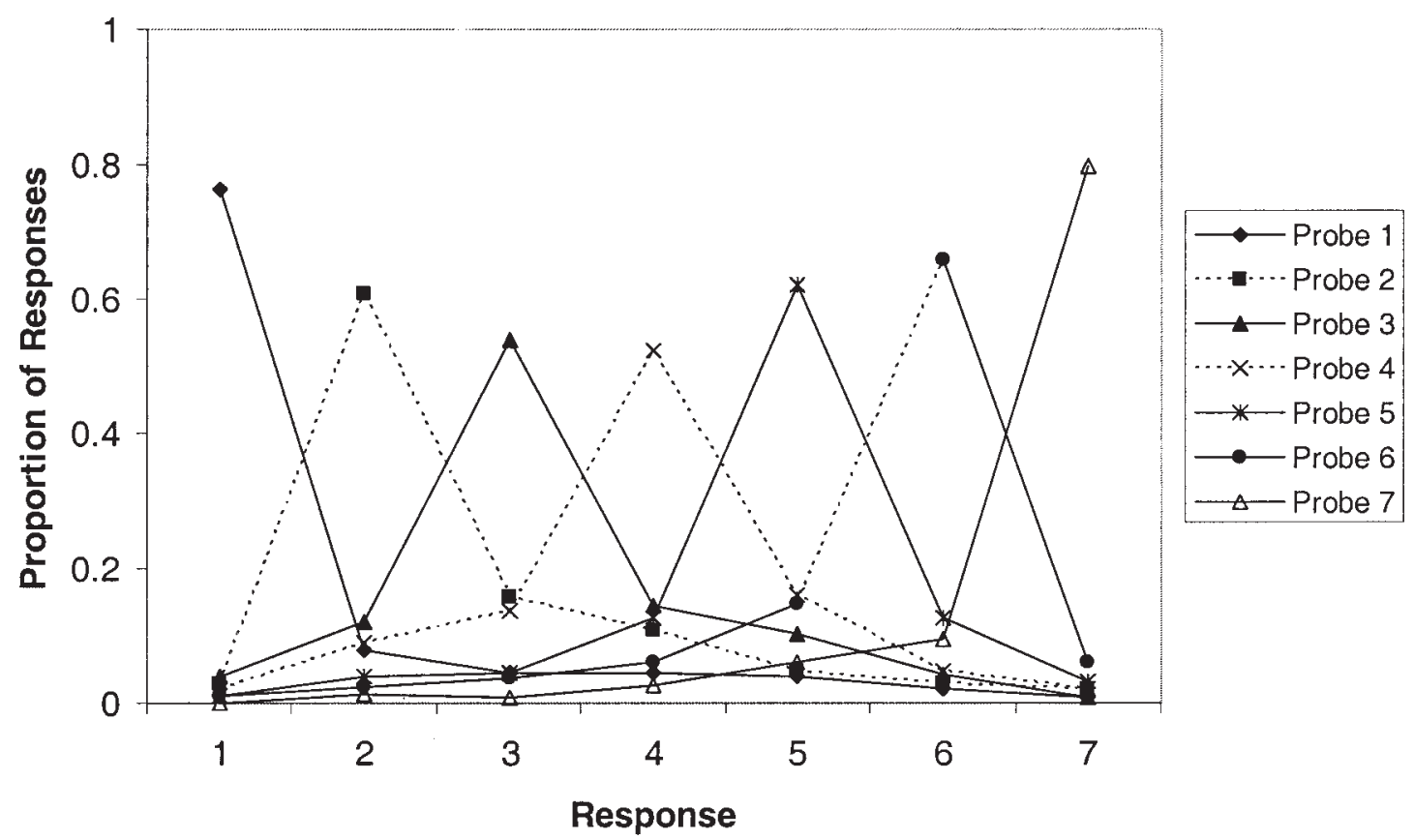

Figure 6. Response gradients as a function of probe position response number in Experiment 3 for patients (A) and controls (B).

that the failure to obtain a schizophrenia-related performance in the line-identification task was due to limited experimental power. An alternative possibility is that the three tasks may have differed in discriminating power (true score variance; Chapman \& Chap- man, 2001; Knight \& Silverstein, 2001; Strauss, 2001). Therefore, we computed the true score variance (Reliability $\times$ Observed Score Variance) for each of the three tasks in control participants. For the duration-identification task, the value was $0.03(0.868 \times$ 
$0.0344)$, for line-length identification it was $0.03(0.782 \times$ $0.0397)$, and for the probed-recall task it was $0.04(0.813 \times$ $0.0514)$. Crucially, an $F$ test of the homogeneity of variance comparing the duration-identification task with the probed serial recall task and comparing the line-length identification task with the probed serial recall task did not find any significant difference between the true score variance of the tasks (in both cases, 0.04/ 0.03 ; thus, $F(20,20)=1.33, n s$. This thus confirms that the deficit in duration identification and probed serial recall compared with line-length identification may represent a genuine differential deficit.

We examined whether the effects were mediated by general intelligence. The impairment remained in Experiment 1 when the WRAT-R score was covaried out, $F(1,37)=12.94, p<.001$, when the Cattell score was covaried out, $F(1,37)=10.23, p<$ .01 , and approached significance at the conventional level when the WAIS-R score was covaried out, $F(1,37)=3.82, p=.058$. Similarly, in Experiment 3, the impairment remained when the WRAT-R was covaried out, $F(1,37)=6.88, p<.01$, and approached significance at the conventional level when the Cattell score was covaried out, $F(1,37)=3.31, p=.077$, but not when the WAIS-R was covaried out, $F(1,37)=1.16, n s$. Thus, it seems unlikely that the effects are mediated entirely by general ability.

A general theoretical account of the findings can be provided in the light of current models of time and memory. The processing resource required by both Experiment 1 and Experiment 3 (where a deficit has occurred) though not in Experiment 2 (no deficit) appears to be that of temporal processing. As we note in the General Discussion below, several recent models assume a connection between memory and timing. If this theoretical relationship is relevant to understanding the results presented here, a particular pattern of intertask correlations would be expected. Specifically, we would expect particularly high correlations between duration-identification and probed-recall performance, as these tasks are hypothesized to involve a common processing component. This correlation should be particularly high in the patient group if the group has an impairment specific to temporal processing. Other intertask correlations may still be significant, reflecting the additional contribution of general processing, in both patient and control groups. For each group, we examined the correlations between levels of overall correct performance on the different tasks. For the patient group, the correlation between duration identification and line identification was not significant ( $r=.406, p=.076$ ), but the correlation between duration identification and probed recall was significant, $(r=.638, p<.01)$, as was the correlation between line identification and probed recall $(r=.488, p<.05)$. For the control group, the correlation between duration identification and line identification was not significant $(r=0.398, p=.083)$, but the correlation between duration identification and probed recall was significant $(r=0.456, p<$ $.05)$. The correlation between line identification and probed recall was not significant ( $r=.381, p=.097$ ). This pattern of correlations is as predicted by the temporal deficit hypothesis, although the only difference between correlations that approached significance was between duration identification-probed recall and duration identification-line identification in the patient group $\left(r_{1}-\right.$ $r_{2}=.232, z=1.34, p=.09$ ).

Both the temporal deficit hypothesis and the global deficit hypothesis predict that, for the patient group, probed-recall performance and line-length identification should not remain corre- lated when duration-identification performance is partialed out. This was true: partial $r(17)=.33, p=.173$. However, the temporal deficit hypothesis, but not the global deficit hypothesis, predicts that the correlation between performance on the durationidentification task and the probed-recall task should remain significant in the patient group when the effect of line-length identification is partialed out. This partial correlation was indeed significant: partial $r(17)=.55, p<.02$.

\section{General Discussion}

The overall aim of the above studies was to use a single experimental methodology to examine potential cognitive deficits associated with schizophrenia over a number of domains. The general pattern of findings was clear: Patients with schizophrenia showed no impairment relative to control participants on a linelength identification task (Experiment 2); yet, they were substantially impaired on a duration-identification task (Experiment 1) and on a task requiring memory for temporal order (Experiment 3 ).

We note that the patients in the current study were on neuroleptics, and the effects on the current tasks of many of the specific drugs that the patients were taking have not been explored. Indeed, the evidence regarding the impact of medication on working memory in schizophrenia in general has not reached a consensus. However, there is some evidence that short-term serial recall performance deficits in patients with schizophrenia are not simply medication artifacts (Elvevåg, Weinberger, \& Goldberg, 2002), and, indeed, deficits in this domain have been reported in medication-free schizophrenic patients (e.g., Meyer-Lindenberg et al., 2001). Nonetheless, the effect on patients with schizophrenia of drugs that manipulate dopaminergic and cholinergic systems warrants examination in a patient sample in which this is possible and in which there is the statistical power to evaluate the effect of such modulation. Clearly, further research is necessary to establish whether such medication does contribute to the current performance profile in schizophrenia.

Overall, we interpret the pattern of results we have obtained as consistent with the notion that schizophrenia is associated with a selective impairment in temporal processing ability that may manifest itself in a variety of tasks for which temporal processing is implicitly or explicitly required. The observed results are consistent with current theoretical developments. Indeed, several recent models of memory have pointed to a close theoretical link between temporal processing and memory, and, indeed, some models explicitly assume that the processes that underpin the maintenance of temporal order information (e.g., in tasks that assess memory for serial order) are closely akin to processes involved in making explicit judgments about temporal durations (e.g., Brown \& Chater, 2001; Brown et al., 2000; Brown et al., 2002; Brown \& Vousden, 1998; see also Burgess \& Hitch, 1992, 1999; Church \& Broadbent, 1990; Gallistel, 1990; Gallistel \& Gibbon, 2000). Both the observed deficits and the pattern of observed partial correlations that we have obtained in the current study are consistent with this interpretation.

\section{References}

American Psychiatric Association. (1994). Diagnostic and statistical manual of mental disorders (4th ed.). Washington, DC: Author.

Berliner, J. E., Durlach, N. I., \& Braida, L. D. (1977). Intensity perception: 
VII. Further data on roving-level discrimination and the resolution and bias edge effects. Journal of the Acoustical Society of America, 61, 1577-1585.

Brown, G. D. A., \& Chater, N. (2001). The chronological organization of memory: Common psychological foundations for remembering and timing. In C. Hoerl \& T. McCormack (Eds.), Time and memory: Issues in philosophy and psychology (pp. 77-110). New York: Oxford University Press.

Brown, G. D. A., Neath, I., \& Chater, N. (2002). A ratio model of scale-invariant memory and identification. Manuscript submitted for publication.

Brown, G. D. A., Preece, T., \& Hulme, C. (2000). Oscillator-based memory for serial order. Psychological Review, 107, 127-181.

Brown, G. D . A., \& Vousden, J. I. (1998). Adaptive analysis of sequential behaviour: Oscillators as rational mechanisms. In M. Oaksford \& N. Chater (Eds.), Rational models of cognition (pp. 165-193). Oxford, England: Oxford University Press

Burgess, N., \& Hitch, G. J. (1992). Towards a network model of the articulatory loop. Journal of Memory and Language, 31, 429-460.

Burgess, N., \& Hitch, G. J. (1999). Memory for serial order: A network model of the phonological loop and its timing. Psychological Review, 106, 551-581.

Cattell, R. B. (1971). Abilities: Their structure, growth and action. Boston: Houghton-Mifflin.

Chapman, L. J., \& Chapman, J. P. (2001). Commentary on two articles concerning generalized and specific cognitive deficits. Journal of Abnormal Psychology, 110, 31-39.

Church, R. M., \& Broadbent, H. (1990). Alternative representations of time, number, and rate. Cognition, 37, 55-81.

Crowder, R. G. (1976). Principles of learning and memory. Hillsdale, NJ: Erlbaum.

Droit-Volet, S., Clement, A., \& Wearden, J. (2001). Temporal generalization in 3- to 8-year-old children. Journal of Experimental Child Psychology, 80, 271-288.

Elvevåg, B., Fisher, J. E., \& Goldberg, T. E. (2003). Probed recall for serial order deficits in short-term memory in schizophrenic patients. Schizophrenia Research, 59, 127-135.

Elvevåg, B., \& Goldberg, T. E. (2000). Cognitive impairment in schizophrenia is the core of the disorder. Critical Reviews in Neurobiology, 14, $1-21$.

Elvevåg, B., McCormack, T., Gilbert, A., Brown, G. D. A., Weinberger, D. R., \& Goldberg, T. E. (2003). Duration judgments in patients with schizophrenia. Psychological Medicine, 33, 1249-1261.

Elvevåg, B., Weinberger, D. R., \& Goldberg, T. E. (2001). Short-term memory for serial order in schizophrenia: A detailed examination of error types. Neuropsychology, 15, 128-135.

Elvevåg, B., Weinberger, D. R., \& Goldberg, T. E. (2002). The phonological similarity effect in short-term memory serial recall in schizophrenia. Psychiatry Research, 112, 77-81.

Gallistel, C. (1990). The organization of learning. Cambridge, MA: MIT Press.

Gallistel, C. R., \& Gibbon, J. (2000). Time, rate, and conditioning. Psychological Review, 107, 289-344.

Goldberg, T. E., Torrey, E. F., Gold, J. M., Bigelow, L. B., Ragland, R. D., Taylor, E., \& Weinberger, D. R. (1995). Genetic risk of neuropsychological impairment in schizophrenia: A study of monozygotic twins discordant and concordant for the disorder. Schizophrenia Research, 17, $77-84$.

Hoerl, C., \& McCormack, T. (2001). Perspectives of time and memory: An introduction. In C. Hoerl \& T. McCormack (Eds.), Time and memory: Issues in philosophy and psychology (pp. 1-33). New York: Oxford University Press.

Holm, S. (1979). A simple sequentially rejective multiple test procedure. Scandinavian Journal of Statistics, 6, 65-70.
Institute for Personality and Ability Testing. (1973). Measuring intelligence with the Culture Fair Test. Champaign, IL: Author.

James, W., \& Stein, C. (1961). Estimation with quadratic loss. Proceedings of the Fourth Berkley Symposium on Mathematics and Statistics, 1, 361-379.

Jastak, S., \& Wilkinson, G. S. (1984). The Wide Range Achievement Test-Revised administration manual (rev. ed.). Wilmington, DE: Jastak Association.

Javitt, D. C., Liederman, E., Cienfuegos, A., \& Shelley, A. M. (1999). Panmodal processing imprecision as a basis for dysfunction of transient memory storage systems in schizophrenia. Schizophrenia Bulletin, 25, 763-775.

Javitt, D. C., Strous, R. D., Grochowski, S., Ritter, W., \& Cowan, N. (1997). Impaired precision, but normal retention, of auditory sensory ("echoic") memory information in schizophrenia. Journal of Abnormal Psychology, 106, 315-324.

Johnson, D. M. (1952). The central tendency of judgment as a regression phenomenon. American Psychologist, 7, 281.

Kaufman, A. S. (1990). Assessing adolescent and adult intelligence. Needham, MA: Allyn \& Bacon.

Knight, R. A., \& Silverstein, S. M. (2001). A process-oriented approach for averting confounds resulting from general performance deficiencies in schizophrenia. Journal of Abnormal Psychology, 110, 15-30.

Kremen, W. S., Seidman, L. J., Faraone, S. V., Pepple, J. R., Lyons, M. J., \& Tsuang, M. T. (1996). The "3 Rs" and neuropsychological function in schizophrenia: An empirical test of the matching fallacy. Neuropsychology, 10, 22-31.

Lacouture, Y. (1997). Bow, range, and sequential effects in absolute identification: A response-time analysis. Psychological Research, 60, 121-133.

Lhamon, W. T., \& Goldstone, S. (1956). The time sense: Estimation of one second duration by schizophrenic patients. Archives of Neurology and Psychiatry, 76, 625-629.

Luce, R. D., Green, D. M., \& Weber, D. L. (1976). Attention bands in absolute identification. Perception \& Psychophysics, 20, 49-54.

Luce, R. D., Nosofsky, R. M., Green, D. M., \& Smith, A. F. (1982). The bow and sequential effects in absolute identification. Perception \& Psychophysics, 32, 397-408.

McCormack, T., Brown, G. D. A., Maylor, E. A., Darby, R. J., \& Green, D. (1999). Developmental changes in time estimation: Comparing childhood and old age. Developmental Psychology, 35, 1143-1155.

McCormack, T., Brown, G. D. A., Maylor, E. A., Richardson, L. B. N., \& Darby, R. J. (2002). Effects of aging on absolute identification of duration. Psychology and Aging, 17, 363-378.

Meyer-Lindenberg, A., Poline, J. B., Kohn, P. D., Holt, J. L., Egan, M. F., Weinberger, D. R., \& Berman, K. F. (2001). Evidence for abnormal cortical functional connectivity during working memory in schizophrenia. American Journal of Psychiatry, 158, 1809-1817.

Missar, C. D., Gold, J. M., \& Goldberg, T. E. (1994). WAIS-R short forms in chronic schizophrenia. Schizophrenia Research, 12, 247-250.

Murdock, B. B., Jr. (1960). The distinctiveness of stimuli. Psychological Review, 67, 16-31.

Rammsayer, T. (1990). Temporal discrimination in schizophrenic and affective disorders: Evidence for a dopamine-dependent internal clock. International Journal of Neuroscience, 53, 111-120.

Shiffrin, R. M., \& Nosofsky, R. M. (1994). 7 plus or minus 2: A commentary on capacity limitations. Psychological Review, 101, 357-361.

Sndsampler (Version 3.7.1). (2000). [Computer software]. Retrieved from http://www.provide.net/ moorepower/ahg/sndsampler/

Stewart, N., Brown, G. D. A., \& Chater, N. (2002). Identification of simple perceptual stimuli: A new model of absolute identification. Manuscript submitted for publication.

Strauss, M. E. (2001). Demonstrating specific cognitive deficits: A psychometric perspective. Journal of Abnormal Psychology, 110, 6-14. 
SuperLab (1994). (Version 1.68) [Computer software]., San Pedro, CA: Cedrus Corporation.

Tracy, J. I., Monaco, C., McMichael, H., Tyson, K., Chambliss, C., Christensen, H. L., \& Celenz, M. A. (1998). Information-processing characteristics of explicit time estimation by patients with schizophrenia and normal controls. Perceptual and Motor Skills, 86, 515526.

Tysk, L. (1983). Time estimation by healthy subjects and schizophrenic patients: A methodological study. Perceptual and Motor Skills, 56, 983-988.

Underwood, B. J. (1977). Temporal codes for memories: Issues and problems. Hillsdale, NJ: Erlbaum.

Volz, H. P., Nenadic, I., Gaser, C., Rammsayer, T., Häger, F., \& Sauer, H. (2001). Time estimation in schizophrenia: An fMRI study at adjusted levels of difficulty. NeuroReport, 12, 313-316.

Webster, F. R., Goldstone, S., \& Webb, W. W. (1962). Time judgment and schizophrenia: Psychophysical method as a relevant contextual factor. Journal of Psychology, 54, 159-164.
Wechsler, D. (1981). Wechsler Adult Intelligence Scale-Revised. San Antonio, TX: Psychological Corporation.

Wechsler, D. (1987). Wechsler Memory Scale-Revised. San Antonio, TX: Psychological Corporation.

Weickert, T. W., Goldberg, T. E., Gold, J. M., Bigelow, L. B., Egan, M. F., \& Weinberger, D. R. (2000). Cognitive impairments in patients with schizophrenia displaying preserved and compromised intellect. Archives of General Psychiatry, 57, 907-913.

Wiens, A. N., Bryan, J. E., \& Crossen, J. R. (1993). Estimating WAIS-R FSIQ from the National Adult Reading Test-Revised in normal subjects. The Clinical Neuropsychologist, 7, 70-84.

Received May 13, 2003

Revision received January 12, 2004

Accepted January 15, 2004

\section{New Editor Appointed for Journal of Occupational Health Psychology}

The American Psychological Association announces the appointment of Lois E. Tetrick, PhD, as editor of Journal of Occupational Health Psychology for a 5-year term (2006-2010).

As of January 1, 2005, manuscripts should be submitted electronically via the journal's Manuscript Submission Portal (www.apa.org/journals/ocp.html). Authors who are unable to do so should correspond with the editor's office about alternatives:

Lois E. Tetrick, $\mathrm{PhD}$

Incoming Editor, $\mathrm{JOHP}$

George Mason University

Department of Psychology, MSN, 3F5

4400 University Drive, Fairfax, VA 22030

Manuscript submission patterns make the precise date of completion of the 2005 volume uncertain. The current editor, Julian Barling, PhD, will receive and consider manuscripts through December 31, 2004. Should the 2005 volume be completed before that date, manuscripts will be redirected to the new editor for consideration in the 2006 volume. 